\title{
Short Communication: Evaluation of the Overall Accuracy of the DeLaval Cell Counter for Somatic Cell Count in Ovine Milk: Effect of Soak Time in Diluted and Undiluted Milk Samples
}

\author{
C. Gonzalo, ${ }^{1}$ B. Linage, J. A. Carriedo, and L. F. De La Fuente \\ Departamento de Producción Animal, Facultad de Veterinaria, Campus de Vegazana, Universidad de León, 24071-León, Spain
}

\begin{abstract}
This study evaluated the performance of the DeLaval cell counter (DCC) when analyzing ovine milk with different soak times (defined as the permanence time of samples within the DCC cassette before starting the DCC counting procedure) in diluted and undiluted milk samples in 2 dairy sheep breeds. A total of 101 composite ovine milk samples (50 from Assaf ewes and 51 from Churra ewes), ranging between $50 \times 10^{3}$ and $2,200 \times$ $10^{3}$ cells $/ \mathrm{mL}$, were divided into 10 aliquots/milk to be analyzed by DCC. Four undiluted aliquots and 4 aliquots diluted 1:1 in PBS were analyzed by using soak times of $0,1,2$, and $3 \mathrm{~min} /$ aliquot, and the other 2 aliquots were diluted 1:1 in propidium iodide or ethidium bromide staining solutions and analyzed by DCC. Milk samples were also analyzed by the Fossomatic method, as a reference. All analyses were carried out in duplicate. Undiluted milk samples with soak times $\geq 1$ min showed large coefficients of regression ( $b=0.96$ to 0.98 ) and correlation ( $r>0.99)$ when compared with the Fossomatic method. In these samples, DCC gave repeatability standard deviations $\left(\mathrm{s}_{\mathrm{r}}=35\right.$ to $51 \times 10^{3}$ cells $/ \mathrm{mL}$ ) lower than other DCC analytical conditions $\left(\mathrm{s}_{\mathrm{r}}=49\right.$ to $74 \times 10^{3}$ cells $\left./ \mathrm{mL}\right)$, and their $\log \mathrm{SCC}$ means (5.51 to 5.52) were close to the reference value (5.56). The log SCC means corresponding to samples diluted $1: 1$ in staining solutions (5.55) did not differ from the reference value; however, these aliquots had lower regression coefficients (b: 0.92 to 0.93 ). Samples diluted 1:1 in PBS and undiluted samples with a 0-min soak time showed a global accuracy similar to or lower than undiluted samples with soak times $\geq 1 \mathrm{~min}$. Breed did not seem to affect the results. We concluded that undiluted raw milk with a soak time $\geq 1$ min and analyzed by DCC shows suitable overall accuracy in ovine milk compared with the reference method and can be consid-
\end{abstract}

Received January 17, 2008.

Accepted April 12, 2008.

${ }^{1}$ Corresponding author: c.gonzalo@unileon.es ered as the best option for on-farm use from an operational point of view.

Key words: sheep milk, somatic cell count, DeLaval cell counter, accuracy

The DeLaval cell counter (DCC; DeLaval International AB, Tumba, Sweden) has been successfully designed for SCC determination in raw bovine milk (DeLaval, 2003) and goat milk (Berry and Broughan, 2007), and some attempts have been carried out to evaluate the accuracy of DCC in ovine milk. In a previous investigation of DCC performance in ovine milk (Gonzalo et al., 2006), raw samples showed lower global accuracy than diluted samples. Dilution in PBS could be enough to guarantee acceptable precision for on-farm practical purposes, although accuracy was improved when PBS was enriched with DNA-specific stains, such as ethidium bromide (EB) or propidium iodide (PI). The poor performance observed in undiluted ovine milk compared with bovine milk and with diluted ovine milk seemed to indicate some DCC difficulties for counting milk with an elevated solids content. High fat and protein content might interfere with both cell stimulation and cell pulse emission and produce small SCC values. Milk dilution could optimize cell nuclei staining and increase the accuracy and repeatability of the DCC method (Gonzalo et al., 2006).

Additional unpublished pilot studies (C. Gonzalo and B. Linage) carried out in undiluted ovine raw milk evidenced a significant effect of an effective Triton content within cassettes on SCC. Once an effective Triton concentration is guaranteed, higher SCC were obtained when milk stayed within the cassette for 1 or $2 \mathrm{~min}$ before analysis. This soak time could be needed to complete the cell nuclei staining in ovine milk and could significantly affect DCC accuracy. Consequently, an attempt should be made to evaluate the effect of soak time on the accuracy of the DCC method for SCC in ovine milk. Thus, the objective of this study was to determine the overall accuracy of DCC in ovine milk in 2 dairy breeds with different solid contents, compared with the Fossomatic SCC (FSCC) method, in 
diluted and undiluted milk samples under 4 soak times $(0,1,2$, and $3 \mathrm{~min})$ before starting the DCC counting procedure. In addition, diluted milk in PI and EB staining solutions were used for comparison.

From 50 Assaf ewes and 51 Churra ewes in different stages of lactation, a total of 101 composite ovine milk samples ranging between $50 \times 10^{3}$ and $2,200 \times 10^{3}$ cells/ $\mathrm{mL}$ were divided into 10 aliquots designed to study the effect of 4 soak times in diluted and undiluted milk samples. Soak time was defined as the permanence time of diluted or undiluted milk within the DCC cassette, before starting the DCC counting procedure (by pushing the Run button). These aliquots were as follows: 1) 4 aliquots of undiluted milk analyzed by DCC with 0 min (DCC-0 min), 1 min (DCC-1 min), 2 min (DCC-2 $\mathrm{min}$ ), and $3 \mathrm{~min}$ (DCC-3 $\mathrm{min}$ ) of soak time, respectively; 2) 4 aliquots of milk diluted 1:1 in PBS and analyzed by DCC with 0 min (DCC-1:1-0 min), 1 min (DCC-1:1$1 \mathrm{~min}$ ), 2 min (DCC-1:1-2 min), and $3 \mathrm{~min}$ (DCC-1:13 min) of soak time; and 3) 2 aliquots of milk diluted 1:1 in PI and EB staining solutions and analyzed by DCC with 0 min of soak time (DCC-1:1-PISS and DCC1:1-EBSS). According to a previous study (Gonzalo et al., 2006), these staining solutions were PBS + PI (0.025 $\mathrm{mg} / \mathrm{mL})+$ Triton X-100 (0.2\%), and PBS + EB $(0.025$ $\mathrm{mg} / \mathrm{mL})+$ Triton $\mathrm{X}-100(0.2 \%)$, respectively, for each aliquot. Samples were charged into the DCC cassette immediately after careful mixing by inverting them 15 times according to the manufacturer's instructions. Raw milk samples were also analyzed by a Fossomatic 5000 instrument (Foss Electric, Hillerød, Denmark). All analyses were carried out in duplicate. The DCC analyses were conducted in the laboratory at ambient temperature within $4 \mathrm{~h}$ postcollection. Milk was heated to $40^{\circ} \mathrm{C}$ before FSCC determination, which was carried out within $24 \mathrm{~h}$ postcollection. Before and during the experiment, the accuracy and linearity of the FSCC method were calibrated by using bovine milk standards of known SCC (between 0 and $2,000 \times 10^{3}$ cells $/ \mathrm{mL}$ ) provided by Cecalait (Poligny, France), so that milk samples analyzed were within the range covered by the DCC evaluation. Fat, protein, and solids contents also were determined in duplicate in all samples by a MilkoScan FT 6000 instrument (Foss Electric).

The 10 DCC analytical conditions were compared with the FSCC method according to 3 types of statistical studies: means comparison, standard deviations of repeatability, and regression. Means comparison was carried out by using the general linear model (procedure GLM; SAS Institute Inc., Cary NC). The statistical model used was

$$
\mathrm{Y}_{\mathrm{ijkl}}=\mu+\mathrm{B}_{\mathrm{i}}+\mathrm{E}_{\mathrm{j}(\mathrm{i})}+\mathrm{A}_{\mathrm{k}}+\mathrm{BA}_{\mathrm{ik}}+\mathrm{e}_{\mathrm{ijkl}},
$$

where $Y_{i j k l}$ is the dependent variable $\log$ SCC, $\mu$ is the mean, $B_{i}$ is the breed effect (Churra and Assaf breeds); $E_{j(i)}$ is the effect of ewe ( $n=51$ for the Churra breed, $\mathrm{n}=50$ for the Assaf breed, and $\mathrm{n}=101$ for the total), $\mathrm{A}_{\mathrm{k}}$ is the effect of 11 previously defined analytical conditions (10 DCC analytical conditions and FSCC), $\mathrm{BA}_{\mathrm{ik}}$ is the breed $\times$ analytical condition interaction, and $\mathrm{e}_{\mathrm{ijkl}}$ is the residual effect, in which 2 replicates were considered because analytical determinations were performed in duplicate. The contrasts for differences among means were carried out in each breed and in the total.

The standard deviation of repeatability $\left(\mathrm{s}_{\mathrm{r}}\right.$ and its relative value, $\mathrm{s}_{\mathrm{r}} \times 100 \sqrt{x}$, where $\bar{x}$ is the arithmetic mean of the SCC) for each of 11 analytical conditions was calculated according to International Dairy Federation standard 128A (International Dairy Federation, 1999) by using the formula

$$
s_{r}=\left(\frac{1}{2 q} \sum_{i=1}^{q} w_{i}^{2}\right)^{1 / 2}
$$

where $q$ is the number of samples and $w_{i}$ is the absolute difference between duplicate results of SCC methods. Standard deviations of repeatability were estimated for each breed and for the total.

Linear regression was performed to establish the relationship between FSCC, used as the reference method, and each of the analytical conditions considered. Because the SCC analytical conditions were carried out in duplicate for DCC and FSCC, the arithmetic mean of the 2 replicates was determined beforehand. Estimates were carried out from 101 observations (pairs of data) for each regression line, and from 51 and 50 observations for the Churra and Assaf breeds, respectively. The corresponding intercept (a), coefficient of regression (b), and coefficient of determination $\left(R^{2}\right)$ were estimated in all cases by using regression (procedure REG; SAS Institute Inc.).

Differences between breeds for fat, protein, and solid contents were studied according to the general linear model (procedure GLM; SAS Institute Inc.) by using a mathematical model, with the breed and ewe within breed as variation factors for each compositional variable.

Based on the first statistical model on SCC variation factors, ewe and SCC analytical condition contributed notably $(P<0.001)$ to SCC variation; the breed $\times$ analytical condition interaction $(F=1.98 ; P<0.05)$ was also a significant but less important effect. Breed factor was not significant $(F=0.06 ; P>0.05)$. In a second ANOVA, statistical analysis showed a significant effect of breed factor on composition variables. Churra ewes had higher $(P<0.001)$ fat $(6.74 \pm 0.01 \%)$, protein $(5.74 \pm$ $0.01 \%)$, and total solids $(18.14 \pm 0.04 \%)$ contents than 
Table 1. Least squares means (LSM) of log SCC, geometric means (GM) of the SCC, and standard deviation of repeatability $\left(\mathrm{s}_{\mathrm{r}}\right.$ and $\mathrm{s}_{\mathrm{r}} \%$ ) for each of 10 analytical conditions analyzed by the DeLaval cell counter (DCC) in the Churra $(\mathrm{n}=51)$ and Assaf $(\mathrm{n}=50)$ breeds and in the total $(\mathrm{n}=101)$, including Fossomatic values (FSCC) as a reference

\begin{tabular}{|c|c|c|c|c|c|c|c|c|c|c|c|c|}
\hline \multirow[b]{2}{*}{$\begin{array}{l}\text { Analytical } \\
\text { condition }^{1}\end{array}$} & \multicolumn{4}{|c|}{ Churra } & \multicolumn{4}{|c|}{ Assaf } & \multicolumn{4}{|c|}{ Total } \\
\hline & $\begin{array}{c}\mathrm{LSM}^{2} \\
(\log \mathrm{SCC})\end{array}$ & $\mathrm{GM}^{3}$ & $\mathrm{~s}_{\mathrm{r}}^{3}$ & $\mathrm{~s}_{\mathrm{r}} \%$ & $\begin{array}{c}\mathrm{LSM}^{4} \\
(\log \mathrm{SCC})\end{array}$ & $\mathrm{GM}^{3}$ & $\mathrm{~s}_{\mathrm{r}}^{3}$ & $\mathrm{~s}_{\mathrm{r}} \%$ & $\begin{array}{c}\mathrm{LSM}^{5} \\
(\log \mathrm{SCC})\end{array}$ & $\mathrm{GM}^{3}$ & $\mathrm{~s}_{\mathrm{r}}^{3}$ & $\mathrm{~s}_{\mathrm{r}} \%$ \\
\hline FSCC & $5.560^{\mathrm{a}}$ & 364 & 13 & 2.30 & $5.554^{\mathrm{a}}$ & 358 & 13 & 2.36 & $5.557^{\mathrm{a}}$ & 360 & 13 & 2.33 \\
\hline DCC-0 min & $5.431^{\mathrm{g}}$ & 272 & 88 & 21.41 & $5.456^{\mathrm{e}}$ & 287 & 56 & 13.43 & $5.444^{\mathrm{f}}$ & 279 & 74 & 17.87 \\
\hline $\mathrm{CC}$ & $5.517^{\mathrm{cd}}$ & 330 & 37 & 7.52 & $5.514^{\text {bc }}$ & 327 & 43 & 8.67 & $5.515^{\text {bc }}$ & 328 & 40 & 8.10 \\
\hline DCC-2 & $5.512^{\mathrm{def}}$ & 326 & 57 & 11.42 & $5.513^{\text {bc }}$ & 327 & 44 & 8.89 & $5.512^{\mathrm{bc}}$ & 326 & 51 & 10.26 \\
\hline DCC-3 min & $5.514^{\mathrm{de}}$ & 327 & 35 & 6.99 & $5.518^{\mathrm{b}}$ & 330 & 35 & 7.10 & $5.516^{\mathrm{bc}}$ & 329 & 35 & 7.04 \\
\hline DCC-1:1-0 $\min$ & $5.534^{\mathrm{bc}}$ & 344 & 51 & 10.00 & $5.515^{\mathrm{bc}}$ & 329 & 56 & 11.45 & $5.525^{\mathrm{b}}$ & 337 & 54 & 10.80 \\
\hline DCC-1:1-1 min & $5.511^{\mathrm{def}}$ & 326 & 66 & 13.55 & $5.503^{b c}$ & 321 & 66 & 13.89 & $5.507^{\mathrm{cd}}$ & 323 & 66 & 13.72 \\
\hline DCC-1:1 & $5.497^{\mathrm{ef}}$ & 316 & 64 & 13.50 & $5.501^{\mathrm{c}}$ & 319 & 71 & 15.23 & $5.499^{\mathrm{de}}$ & 317 & 68 & 14.4 \\
\hline DCC-1:1 & $5.494^{\mathrm{f}}$ & 314 & 48 & 10.37 & $5.479^{\mathrm{d}}$ & 302 & 51 & 11.5 & $5.486^{\mathrm{e}}$ & 308 & 49 & 10.8 \\
\hline DCC-1:1-PISS & $5.551^{\mathrm{ab}}$ & 356 & 82 & 15.68 & $5.542^{\mathrm{a}}$ & 350 & 56 & 10.94 & $5.545^{\mathrm{a}}$ & 352 & 70 & 13.54 \\
\hline DCC-1:1-EBSS & $5.549^{\mathrm{ab}}$ & 353 & 65 & 12.45 & $5.558^{\mathrm{a}}$ & 361 & 56 & 10.71 & $5.550^{\mathrm{a}}$ & 357 & 60 & 11.49 \\
\hline
\end{tabular}

${ }^{\mathrm{a}-\mathrm{g}}$ Means within LSM column not sharing a common superscript letter differ $(P<0.05)$.

${ }^{1}$ FSCC = undiluted aliquots analyzed by Fossomatic; DCC-0 min = undiluted aliquots analyzed by DCC with 0 min of soak time; DCC-1 min = undiluted aliquots analyzed by DCC with 1 min of soak time; DCC$2 \mathrm{~min}=$ undiluted aliquots analyzed by DCC with $2 \mathrm{~min}$ of soak time; DCC-3 $\mathrm{min}=$ undiluted aliquots analyzed by DCC with 3 min of soak time; DCC-1:1-0 min = aliquots diluted 1:1 in PBS and analyzed by DCC with 0 min of soak time; DCC-1:1-1 min = aliquots diluted 1:1 in PBS and analyzed by DCC with 1 min of soak time; DCC-1:1-2 min = aliquots diluted 1:1 in PBS and analyzed by DCC with 2 min of soak time; DCC-1:1-3 min = aliquots diluted 1:1 in PBS and analyzed by DCC with 3 min of soak time; DCC1:1-PISS = aliquots diluted 1:1 in propidium iodide staining solution and analyzed by DCC; DCC-1:1-EBSS = aliquots diluted 1:1 in ethidium bromide staining solution and analyzed by DCC.

${ }^{2}$ SE of LSM: 0.007 .

${ }^{3}$ Values $\times 10^{3}$ cells $/ \mathrm{mL}$.

${ }^{4}$ SE of LSM: 0.006 .

${ }^{5} \mathrm{SE}$ of LSM: 0.004 .

Assaf ewes $(5.40 \pm 0.01 \%, 5.25 \pm 0.01 \%$, and $16.17 \pm$ $0.04 \%$, respectively).

Table 1 shows the comparison of SCC mean values obtained for the analytical conditions and methods assayed in ovine milk. The SCC values obtained by the FSCC method (log SCC: 5.56; geometric means: $360 \times$ $10^{3}$ cells $\left./ \mathrm{mL}\right)$ were similar $(P>0.05)$ to those obtained by DCC in samples diluted 1:1 in PISS or EBSS (log SCC: 5.55 ; geometric means: 352 to $357 \times 10^{3}$ cells $/ \mathrm{mL}$ ), and were slightly greater $(P<0.05)$ than those obtained in undiluted aliquots with soak times $\geq 1 \mathrm{~min}$ (log SCC: 5.51 to 5.52; geometric means: 326 to $329 \times 10^{3}$ cells/ $\mathrm{mL}$ ) or in aliquots diluted 1:1 in PBS with soak times $\leq 1 \mathrm{~min}$ (log SCC: 5.51 to 5.53; geometric means: 323 to $337 \times 10^{3}$ cells $/ \mathrm{mL}$ ). The accuracy losses were $>10 \%$ for the other diluted aliquots (DCC-1:1-2 min, DCC-1:1-3 min) when compared with FSCC reference values. The greatest SCC difference was $>20 \%$ for undiluted sample with 0 min of soak time (DCC-0 min), in accord with previous results (Gonzalo et al., 2006), so undiluted ovine milk should not be analyzed immediately after loading the milk into the DCC cassette. These differences among aliquots were very similar for both dairy sheep breeds, as shown in Table 1.
Regarding repeated SCC, standard deviations of repeatability are given in Table 1 . Within the DCC method, the lower values were for undiluted ovine milk analyzed with soak times $\geq 1 \mathrm{~min}\left(\mathrm{~s}_{\mathrm{r}} \%=7.04\right.$ to $\left.10.26 \%\right)$. When an erratic sample belonging to the Churra breed was deleted, $\mathrm{s}_{\mathrm{r}} \%$ values were very similar (6.99 to $8.66 \%$ ) in all 3 undiluted aliquots with soak times $\geq 1$ min, which represented the more repeatable DCC analytical conditions. These $\mathrm{s}_{\mathrm{r}} \%$ values were close to values obtained for the direct microscopic method in ovine milk (Gonzalo et al., 2003, 2004). Standard deviations of repeatability were large for all other aliquots (10.80 to $17.87 \%)$. Similar values were obtained for both breeds, although the Churra breed showed $\mathrm{s}_{\mathrm{r}} \%$ values $(21.41 \%)$ greater than those of the Assaf breed (13.43\%) for undiluted samples with 0 min of soak time (DCC-0 min). This difference could be explained by the higher total solids content of milk from Churra ewes. High fat and protein contents might interfere with both cell stimulation and cell pulse emission and reduce DCC global accuracy. High $\mathrm{s}_{\mathrm{r}} \%$ values (12.6 to $19.6 \%$ ) were also obtained in ovine raw milk analyzed by DCC immediately after loading in a previous study (Gonzalo et al., 2006). The $\mathrm{s}_{\mathrm{r}} \%$ values found in diluted samples were 
Table 2. Coefficients of regression (b), intercept (a), standard errors (SE), and $R^{2}$ values based on linear regression analyses between Fossomatic (as a reference method) and DCC analytical conditions studied in the Churra $(\mathrm{n}=51)$ and Assaf $(\mathrm{n}=50)$ breeds, and in the total $(\mathrm{n}=101)$

\begin{tabular}{|c|c|c|c|c|c|c|c|c|c|}
\hline \multirow{3}{*}{$\begin{array}{l}\text { Analytical } \\
\text { conditions }^{1}\end{array}$} & \multicolumn{9}{|c|}{ Regression with Fossomatic method $(y=b x+a)$} \\
\hline & \multicolumn{3}{|c|}{ Churra } & \multicolumn{3}{|c|}{ Assaf } & \multicolumn{3}{|c|}{ Total } \\
\hline & $\mathrm{b}$ & a & $\mathrm{R}^{2}$ & $\mathrm{~b}$ & a & $\mathrm{R}^{2}$ & $\mathrm{~b}$ & a & $\mathrm{R}^{2}$ \\
\hline DCC-0 min & 0.930 & 0.266 & 0.955 & 0.915 & 0.376 & 0.968 & 0.922 & 0.320 & 0.959 \\
\hline $\mathrm{SE}$ & 0.029 & 0.161 & - & 0.024 & 0.134 & - & 0.019 & 0.106 & - \\
\hline DCC-1 min & 0.947 & 0.252 & 0.992 & 0.978 & 0.080 & 0.992 & 0.962 & 0.170 & 0.991 \\
\hline $\mathrm{SE}$ & 0.012 & 0.068 & - & 0.013 & 0.072 & - & 0.009 & 0.060 & - \\
\hline DCC-2 min & 0.979 & 0.070 & 0.989 & 0.984 & 0.048 & 0.992 & 0.981 & 0.060 & 0.990 \\
\hline $\mathrm{SE}$ & 0.015 & 0.084 & - & 0.013 & 0.070 & - & 0.010 & 0.055 & - \\
\hline DCC-3 min & 0.977 & 0.082 & 0.985 & 0.966 & 0.155 & 0.992 & 0.971 & 0.118 & 0.988 \\
\hline $\mathrm{SE}$ & 0.017 & 0.096 & - & 0.012 & 0.068 & - & 0.011 & 0.059 & - \\
\hline DCC-1:1-0 min & 0.930 & 0.362 & 0.972 & 0.941 & 0.288 & 0.979 & 0.936 & 0.326 & 0.975 \\
\hline $\mathrm{SE}$ & 0.022 & 0.126 & - & 0.020 & 0.110 & - & 0.015 & 0.083 & - \\
\hline DCC-1:1-1 min & 0.963 & 0.159 & 0.975 & 0.962 & 0.164 & 0.980 & 0.962 & 0.162 & 0.977 \\
\hline $\mathrm{SE}$ & 0.022 & 0.123 & - & 0.020 & 0.111 & - & 0.015 & 0.082 & - \\
\hline DCC-1:1-2 min & 0.963 & 0.143 & 0.967 & 0.935 & 0.309 & 0.988 & 0.949 & 0.224 & 0.976 \\
\hline $\mathrm{SE}$ & 0.025 & 0.142 & - & 0.015 & 0.082 & - & 0.015 & 0.083 & - \\
\hline DCC-1:1-3 min & 0.932 & 0.315 & 0.976 & 0.937 & 0.278 & 0.978 & 0.934 & 0.296 & 0.977 \\
\hline $\mathrm{SE}$ & 0.021 & 0.117 & - & 0.020 & 0.112 & - & 0.014 & 0.081 & - \\
\hline DCC-1:1-PISS & 0.916 & 0.457 & 0.969 & 0.936 & 0.343 & 0.982 & 0.926 & 0.402 & 0.975 \\
\hline $\mathrm{SE}$ & 0.023 & 0.130 & - & 0.018 & 0.101 & - & 0.015 & 0.082 & - \\
\hline DCC-1:1-EBSS & 0.923 & 0.415 & 0.960 & 0.909 & 0.512 & 0.977 & 0.916 & 0.463 & 0.967 \\
\hline $\mathrm{SE}$ & 0.027 & 0.149 & - & 0.020 & 0.112 & - & 0.017 & 0.094 & - \\
\hline
\end{tabular}

${ }^{1}$ DCC- 0 min = undiluted aliquots analyzed by DCC with 0 min of soak time; DCC-1 min = undiluted aliquots analyzed by DCC with 1 min of soak time; DCC- 2 min = undiluted aliquots analyzed by DCC with 2 min of soak time; DCC-3 min = undiluted aliquots analyzed by DCC with 3 min of soak time; DCC-1:10 min = aliquots diluted 1:1 in PBS and analyzed by DCC with 0 min of soak time; DCC-1:1-1 min = aliquots diluted 1:1 in PBS and analyzed by DCC with 1 min of soak time; DCC-1:1-2 min = aliquots diluted 1:1 in PBS and analyzed by DCC with 2 min of soak time; DCC-1:1-3 min = aliquots diluted 1:1 in PBS and analyzed by DCC with 3 min of soak time; DCC-1:1-PISS = aliquots diluted 1:1 in propidium iodide staining solution and analyzed by DCC; DCC-1:1-EBSS = aliquots diluted 1:1 in ethidium bromide staining solution and analyzed by DCC.

smaller (10.80 to $14.47 \%$ ) than those obtained in DCC0 min aliquots $(17.87 \%)$, but greater than those obtained in the above-mentioned undiluted aliquots with soak times $\geq 1 \mathrm{~min}$. In this sense, the present study evidenced important relative deviations between SCC replicates for low SCC in diluted samples, although these differences are not very important from a biological point of view because low SCC are indicative of optimal mammary health.

Regression studies between FSCC (reference method) and all DCC analytical conditions assayed are given in Table 2 . The $R^{2}$ values were very large $\left(R^{2} \geq 0.99\right)$ in undiluted samples with soak times $\geq 1$ min (DCC- 1 min, DCC-2 min, and DCC-3 min). These 3 aliquots also showed the greatest coefficients of regression $(b=0.96$ to 0.98 ), coinciding with the smallest intercept values ( $\mathrm{a}=0.06$ to 0.17 ). These values coincided with those reported from a comparison between FSCC and DCC in bovine raw milk $(b=0.96$, and $\mathrm{a}=0.20$; Gonzalo et al., 2006) and from a comparison between the direct microscopic reference method and FSCC for undiluted ovine milk samples (Gonzalo et al., 1993, 2003) and bovine milk samples (Schmidt-Madsen, 1975; Heald et al., 1977) by other authors. The optimal regression was for the DCC-2 min analytical condition, as shown in Table 2. Undiluted milk samples with 0 min of soak time showed a smaller regression coefficient $(b=0.92)$ and a higher intercept $(\mathrm{a}=0.32)$ than other undiluted aliquots. Aliquots diluted in staining solution also had low coefficients of regression ( $b=0.92$ to 0.93 ) and high intercept values ( $\mathrm{a}=0.40$ to 0.46 ). Large intercepts indicated compromised accuracy and repeatability of samples with low SCC, which was evidenced in diluted milk samples. The results of the regression study were very similar for both dairy sheep breeds, as shown in Table 2.

The increased global accuracy observed in undiluted milk with soak times $\geq 1 \mathrm{~min}$, compared with 0 min of soak time, indicates that a latent time is needed after milk loading in the DCC cassette for cellular membrane lysis and cell nuclei staining in ovine milk. Consequently, the soak time in undiluted samples could optimize cell nuclei stimulation and increase the accuracy and repeatability of the DCC method. The dilution of milk in PBS or in staining solutions also improved the accuracy of SCC values, in accordance with previous 
results (Gonzalo et al., 2006), but it worsened the regression performance with the FSCC reference method, particularly for low SCC. Compared with the FSCC method, the small accuracy losses presented by raw milk aliquots with soak times $\geq 1$ min could be assumed for on-farm or other uses, thus increasing the versatility of the DCC method in comparison with the current cumbersome and very expensive SCC counters.

In conclusion, compared with the usual DCC procedure in bovine milk, the results of our study in 2 dairy sheep breeds indicated that DCC accuracy was significantly improved in ovine milk when soak times $\geq 1 \mathrm{~min}$ were applied before starting the counting procedure. For these aliquots, accuracy losses were $<10 \%$; coefficients of regression (b) and correlation ( $\mathrm{r}$ ) obtained from comparisons between the FSCC reference method and DCC were $\geq 0.96$ and $>0.99$, respectively, and standard deviations of repeatability were approximately $8 \%$. Consequently, although other analytical conditions based on the dilution of milk could also be appropriate for DCC analysis, undiluted milk soaked $\geq 1$ min in DCC cassette reagents shows suitable overall accuracy in ovine milk and it is probably the best option for onfarm use from an operational point of view.

\section{ACKNOWLEDGMENTS}

The authors wish to thank DeLaval International AB (Tumba, Sweden) and CENSYRA (National Center for
Animal Breeding and Reproduction, Villaquilambre, León, Spain) for their collaboration.

\section{REFERENCES}

Berry, E., and J. Broughan. 2007. Use of DeLaval cell counter (DCC) on goats' milk. J. Dairy Res. 74:345-348.

DeLaval. 2003. DeLaval cell counter DCC. http://www.delaval.com/ Products/Milking/Cell-counter-DCC/DeLaval_cell-counter-DCC/ default.htm?wbc_purpose=h Accessed May 31, 2007.

Gonzalo, C., J. A. Baro, J. A. Carriedo, and F. San Primitivo. 1993. Use of Fossomatic method to determine somatic cell counts in sheep milk. J. Dairy Sci. 76:115-119.

Gonzalo, C., J. C. Boixo, J. A. Carriedo, and F. San Primitivo. 2004. Evaluation of rapid somatic cell counters under different analytical conditions in ovine milk. J. Dairy Sci. 87:3623-3628.

Gonzalo, C., B. Linage, J. A. Carriedo, F. de la Fuente, and F. San Primitivo. 2006. Evaluation of the overall accuracy of the DeLaval cell counter for somatic cell count in ovine milk. J. Dairy Sci. 89:4613-4619.

Gonzalo, C., J. R. Martínez, J. A. Carriedo, and F. San Primitivo. 2003. Fossomatic cell-counting on ewe milk: Comparison with direct microscopy and study of variation factors. J. Dairy Sci. $86: 138-145$.

Heald, C. W., G. M. Jones, S. C. Nickerson, W. N. Patterson, and W. E. Vinson. 1977. Preliminary evaluation of the Fossomatic somatic cell counter for analysis of individual cow samples in a central testing laboratory. J. Food Prot. 40:523-526.

International Dairy Federation. 1999. Definition and evaluation of the overall accuracy of indirect methods of milk analysis application to calibration procedure and quality control in the dairy laboratory. FIL-IDF Standard no. 128A. Int. Dairy Fed., Brussels, Belgium.

Schmidt-Madsen, P. 1975. Fluoro-opto-electronic cell-counting on milk. J. Dairy Res. 42:227-239. 